\title{
The AAOS 2019 Clinical Practice Guidelines for the Management of Rotator Cuff Injuries Are Unbiased and Incorporate a Diverse Body of Literature
}

\author{
Jason Lee, B.S., Daniel W. Griepp, B.E., Colin J. Burgess, D.O., Brandon Petrone, D.O., \\ Adam D. Bitterman, D.O., and Randy M. Cohn, M.D.
}

\begin{abstract}
Purpose: To analyze the scientific research that formed the basis of the 2019 American Academy of Orthopaedic Surgeons (AAOS) clinical practice guidelines for the management of rotator cuff injuries. Methods: All studies cited in the 2019 AAOS clinical practice guidelines for the management of rotator cuff injuries were extracted and categorized. Extracted data included type of study, number of patients, level of evidence, journal of publication, impact factor, year of publication, country of origin, contributing authors, affiliated institutions, and significant findings. Data were analyzed to determine time from publication to implementation, level of evidence, and frequency of cited journals and authors. Results: The studies cited in the guideline included 15,130 patients from 140 studies published between 1994 and 2018. The overall mean time from article publication to 2019 AAOS clinical practice guidelines was $4.76 \pm 2.23$ years. Of articles published in 2010 to 2019, 64 studies were cited in the strong recommendation strength subcategory, and 57 articles were cited in the moderate recommendation strength subcategory. Articles published in Journal of Shoulder $\theta$ Elbow Surgery and Arthroscopy were cited most frequently. The most frequent authors were J. H. Oh, R. Z. Tashjian, S. H. Kim, N. Maffulli, and J. C. Yoo. Conclusions: The 2019 AAOS CPG reference a diverse number of journals and authors, appearing to be impartial. Furthermore, prompt time from publication to implementation in the Guidelines indicates that it is possible to influence clinical guidelines with recent work. Clinical Relevance: An analysis of the scientific research that forms the basis of the AAOS Clinical Practice Guidelines for the Management of Rotator Cuff Injuries can provide valuable information about the quality of the Guidelines.
\end{abstract}

\section{Introduction}

I $t$ is widely accepted that the translation of scientific research into clinical practice can be a slow and methodical process. Previous studies have estimated an

From the New York Institute of Technology, College of Medicine, Old Westbury, New York, U.S.A. (J.L., D.W.G.); and Donald and Barbara Zucker School of Medicine at Hofstra/Northwell at Plainview Hospital, Plainview, New York, U.S.A. (J.L., D.W.G., C.J.B., B.P., A.D.B., R.M.C.).

The authors report that they have no conflicts of interest in the authorship and publication of this article. Full ICMJE author disclosure forms are available for this article online, as supplementary material.

Received June 30, 2021; accepted November 16, 2021.

Address correspondence to Randy M. Cohn, M.D., Orthopaedic Surgery Residency Program, Zucker School of Medicine at Hofstra/Northwell, Northwell Orthopaedic Institute at Huntington, Department of Orthopaedic Surgery, 155 East Main St., Huntington, NY, 11743, U.S.A. E-mail: Randymcohn@gmail.com.

(C) 2021 THE AUTHORS. Published by Elsevier Inc. on behalf of the Arthroscopy Association of North America. This is an open access article under the CC BY-NC-ND license (http://creativecommons.org/licenses/by-nc-nd/4.0/). 2666-061X/21924

https://doi.org/10.1016/j.asmr.2021.11.017 average lag of 17 years for new scientific discoveries to enter day-to-day clinical practice. ${ }^{1,2}$ Clinical practice guidelines are an important tool to improve the quality and standardization of care received by patients through the implementation of best clinical practices based on scientific research. However, clinical practice guidelines are difficult to construct and implement, given the high degree of complexity and patient variation that exists in everyday clinical practice. Furthermore, articles may have different outcome measures or patient populations, making the generalizability of findings difficult to report. This is further complicated by the fact that highly specific fields may consist of research published by only a handful of different clinicians, increasing probability of bias in guidelines. Indeed, it may be difficult to produce universal and widely applicable guidelines if only a select group of authors and journals are primarily used. Lastly, although current research is important to guide evidence-based practice, it may potentially reduce the importance of well-established clinical practice that is not reflected in current research. 
For clinical entities in which practice guidelines already exist, there is a need to periodically provide updates as newer research is constantly being published. However, given the amount of time and resources it takes to create and update a clinical practice guideline, it is impractical to constantly revise. Although delaying the implementation of new interventions is necessary to ensure the safety and efficacy of these scientific discoveries, ${ }^{3}$ delays can lead to wasted resources and loss of potential patient benefits. ${ }^{4}$ In March 11, 2019, the clinical practice guidelines for the treatment of rotator cuff tendon repair was published to replace the previously published 2010 guidelines. ${ }^{5}$ The purpose of this study was to analyze the scientific research that formed the basis of the 2019 American Academy of Orthopaedic Surgeons (AAOS) clinical practice guidelines for the management of rotator cuff injuries. Specifically, we considered 1) time from cited article publication to implementation of guidelines, 2) degree to which authors were represented in multiple studies cited in guidelines, 3) which journals were most cited and impactful in the guidelines, and 4) how studies cited in "strong" versus "moderate" level of evidence subcategories compared within guidelines. We hypothesized that articles cited in the AAOS clinical practice guidelines would have relatively short times from publication to implementation, published by a broad range of authors within a diverse group of journals.

\section{Methods}

\section{Approach}

The articles cited in the 2019 AAOS clinical practice guidelines (CPG) for the management of rotator cuff injuries were reviewed to identify possible factors that influence the time of publication to implementation of guidelines.

\section{Search}

National databases (PubMed, Cochrane, Embase, and Google Scholar) were used to retrieve studies cited in the 2019 AAOS CPG for the management of rotator cuff injuries. All studies that were referenced in the CPG in the clinical management subgroups with moderate to strong recommendation strength were reviewed. Strong recommendations are classified as those with "evidence from two or more 'high'-strength studies with consistent findings for recommending for or against the intervention." Moderate recommendations are classified as those with "evidence from two or more 'moderate' strength studies with consistent findings or evidence from a single 'high' quality study for recommending for or against the intervention." ${ }^{\prime 6}$ Guideline subcategories with limited or no reliable evidence were excluded from our analysis.

\section{Screening}

All articles that met the inclusion criteria were reviewed independently by two authors. Disagreements that arose were resolved by referring to the 2019 AAOS CPG. Publications that were cited by multiple clinical guideline subcategories were included in the analysis of all referenced subgroups.

\section{Data Collection and Analysis}

Data were extracted with the following fields used for analysis: type of study, number of patients, level of evidence, journal of publication, impact factor, year of publication, country of origin, contributing authors, affiliated institutions, and significant findings. Studies without a published level of evidence were assigned one based on the classification system issued by The Journal of Bone and Joint Surgery. ${ }^{7}$ This classification system notably divides studies into four groups (therapeutic, prognostic, diagnostic, and economic or decision analysis) and creates five levels (I-V) for each study type, each with their own unique requirements. Because the 2010 CPG for optimizing the management of rotator cuff problems published by the AAOS was considered when developing the 2019 CPG, articles published before 2010 were excluded from our analysis of time from publication to implementation of guideline. Studies published before 2010 were, however, included when analyzing the correlation between journal of publication and implementation of guidelines, as well as frequency of authorship.

\section{Results}

A total of 140 studies, including 15,130 patients, were identified with publication dates between 1994 and 2018. There were 106 studies with 10,739 patients published after 2010, with an overall mean time from article publication to release of the clinical practice guideline of $4.76 \pm 2.23$ years. Among the 106 articles, there were 63 randomized controlled trials (RCTs), 35 prospective studies, and 8 retrospective studies. 64 of these articles were cited by the 2019 AAOS clinical practice guidelines subcategories with strong recommendation strength. Of the 64 articles, 54 are evidence level 1 or 2 studies, and 10 are evidence level 3 or 4 studies. Subcategories with moderate recommendation strength cited 57 articles with 49 evidence level 1 or 2 studies and 8 evidence level 3 or 4 studies. A comprehensive list of the articles may be found in the Full Clinical Practice Guidelines for the Management of Rotator Cuff Injuries.

\section{Guideline Subcategories}

The subcategories of interest were those with strong and moderate strengths of recommendation. A breakdown of studies with a level of evidence of 1 and 2 stratified by subcategory are listed in Tables 1 and 2, 
Table 1. Strong Recommendation Strength Guideline Subcategories

\begin{tabular}{|c|c|c|c|c|c|c|c|c|}
\hline Guideline Subcategory & $n$ Articles & Average Years from 2019 & $n$ Patients & LOE 1 & LOE 2 & $\mathrm{RCT}$ & PS & RS \\
\hline Management of small to medium tears & 2 & $4.50 \pm .71$ & 283 & 2 & 0 & 2 & & \\
\hline Long-term nonoperative management & 3 & $3.67 \pm 1.53$ & 372 & 2 & 1 & 2 & 1 & \\
\hline Diagnosis (clinical examination) & 3 & $3.67 \pm .58$ & 535 & 2 & 1 & 3 & & \\
\hline Diagnosis (imaging) & 11 & $4.45 \pm 2.02$ & 1055 & 5 & 6 & 1 & 8 & 2 \\
\hline Post-op mobilization timing & 6 & $4.67 \pm 1.63$ & 535 & 3 & 3 & 6 & & \\
\hline High-grade partial thickness rotator cuff tears & 4 & $5.25 \pm 1.50$ & 254 & 0 & 4 & 1 & 3 & \\
\hline Prognostic factors (age) & 3 & $4.67 \pm 1.53$ & 302 & 1 & 2 & & 3 & \\
\hline \multicolumn{9}{|l|}{ Prognostic factors (Worker's Compensation) } \\
\hline Biological augmentation with platelet-derived products & 6 & $4.33 \pm 1.97$ & 453 & 5 & 1 & 5 & 1 & \\
\hline Single-row vs double-row repair & 7 & $6.29 \pm 2.36$ & 517 & 5 & 2 & 7 & & \\
\hline Single-row vs double-row repair retears & 6 & $5.83 \pm 2.23$ & 449 & 5 & 1 & 6 & & \\
\hline Open vs arthroscopic repairs & 3 & $3.33 \pm 2.31$ & 473 & 1 & 2 & 3 & & \\
\hline
\end{tabular}

LOE, level of evidence PS, prospective study; ; RCT, randomized controlled trial; RS, retrospective study.

respectively. Of the subcategories with strong recommendation strength, "diagnosis (imaging)" was found to have the greatest number of cited sources and the greatest total number of patients with 15 referenced articles and 1,884 patients. In contrast, "prognostic factors (worker's compensation)" had the least number of citations, referencing only two evidence level 3 studies. "Open vs arthroscopic repairs" had the lowest average time from article publication to clinical practice guidelines implementation date, at $3.33 \pm 2.31$ years. "Diagnosis (imaging)," "biological augmentation with platelet derived products," "single-row vs double-row repair," and "single-row vs double-row repair retears" subcategories all referenced the greatest number of evidence level 1 studies, while "high-grade partial thickness rotator cuff tears" and "prognostic factors (worker's compensation)" cited no evidence level 1 studies. However, it is noted that "biological augmentation with platelet-derived products" and "single-row vs double-row repair re-tears" had the greatest ratio of evidence level 1 studies to total studies (5:6). Finally, "post-op mobilization timing" and "single-row vs double-row repair re-tears" were cited with the greatest number of RCTs, with RCTs constituting all six of the referenced studies in both subcategories.

Of the subcategories with moderate recommendation strength, the "postoperative pain management" subcategory had a substantially greater number of cited articles (35), total patients (2374), evidence level 1 studies (21), and RCTs (30) than the other moderatestrength subcategories. In contrast, "prognostic factors (comorbidities)," "prognostic factors (diabetes)," and "prognostic factors (patient expectations)" all cited no evidence level 1 studies, with "prognostic factors (patient expectations)" citing no articles published in 2010 or later. "Prognostic factors (comorbidities)" cited the least total number of articles, with only a single evidence level 3 study and had the longest average time from article publication to clinical practice guidelines implementation date (9 years). "Prognostic factors (higher BMI)" had the lowest average time from article publication to clinical practice guidelines implementation date, averaging $3.00 \pm 4.00$ years.

\section{Authors}

Among the 140 studies cited by the CPG, there were 662 total contributing authors. Analysis showed first or senior authorship was not shared by the same person for greater than 3 articles per person. Frequency analysis of authors appearing in multiple journals showed F. Franceschi, ${ }^{9-11}$ J. J. Lee, ${ }^{12-14}$ and S. Moosmayer ${ }^{15-17}$ to be first author in 3 articles published in a range of 10 years $(2007-2017)$. R. Z. Tashjian, ${ }^{18-20}$ A. Green, ${ }^{21-23}$ and V. Denaro ${ }^{9-11}$ were each credited as a senior author in 3 articles each, published over a range of 12 years (2006-2018). Frequency analysis of

Table 2. Moderate Recommendation Strength Guideline Subcategories

\begin{tabular}{|c|c|c|c|c|c|c|c|c|}
\hline Guideline Subcategory & $n$ Articles & Average Years from 2019 & $n$ Patients & LOE 1 & LOE 2 & RCT & PS & RS \\
\hline Operative management & 3 & $4.67 \pm .58$ & 339 & 1 & 2 & 2 & 1 & \\
\hline Acromioplasty and rotator cuff repair & 4 & $6.25 \pm 1.5$ & 423 & 2 & 2 & 3 & 1 & \\
\hline Distal clavicle resection & 2 & $6.50 \pm 2.12$ & 161 & 2 & & 2 & & \\
\hline Corticosteroid injections for rotator cuff tears & 4 & $6.50 \pm 2.52$ & 331 & 3 & 1 & 2 & 2 & \\
\hline Prognostic factors (higher BMI) & 1 & $4.00 \pm 0$ & 85 & 1 & & & 1 & \\
\hline \multicolumn{9}{|l|}{ Prognostic factors (comorbidities) } \\
\hline \multicolumn{9}{|l|}{ Prognostic factors (diabetes) } \\
\hline \multicolumn{9}{|l|}{ Prognostic factors (patient expectations) } \\
\hline Postoperative pain management & 35 & $4.83 \pm 2.35$ & 2374 & 21 & 14 & 30 & 5 & \\
\hline
\end{tabular}

BMI, body mass index; LOE, level of evidence; PS, prospective study; RCT, randomized controlled trial; RS, retrospective study. 
Table 3. Journals Cited in Moderate and Strong Recommendation Strength Guideline Subcategories

\begin{tabular}{|c|c|c|c|c|c|c|c|c|c|}
\hline Journal & $\begin{array}{c}n \\
\text { Articles }\end{array}$ & $\begin{array}{c}n \\
\text { Patients }\end{array}$ & $\begin{array}{c}\text { Mean } \\
\text { Patients } \\
\text { per Study }\end{array}$ & LOE 1 & LOE 2 & LOE 3 & LOE 4 & 2019 IF & Country \\
\hline Journal of Shoulder $\theta$ Elbow Surgery & 19 & 2273 & 120 & 8 & 7 & 4 & & 2.817 & USA \\
\hline Arthroscopy: Journal of Arthroscopic and Related Surgery & 18 & 1168 & 65 & 8 & 9 & & 1 & 4.325 & USA \\
\hline American Journal of Sports Medicine & 13 & 1509 & 116 & 9 & 2 & 1 & 1 & 5.810 & USA \\
\hline Journal of Bone and Joint Surgery & 12 & 2375 & 198 & 10 & 1 & 1 & & 4.578 & USA \\
\hline Knee Surgery, Sports Traumatology, Arthroscopy & 9 & 757 & 84 & 6 & 3 & & & 3.166 & Germany \\
\hline Radiology & 5 & 377 & 75 & 1 & 3 & 1 & & 7.931 & USA \\
\hline Archives of Orthopaedic and Trauma Surgery & 4 & 454 & 114 & 2 & & 2 & & 2.021 & Germany \\
\hline Skeletal Radiology & 4 & 567 & 142 & 2 & & 2 & & 1.618 & Germany \\
\hline Anesthesia $\theta$ Analgesia & 3 & 180 & 60 & 1 & 2 & & & 4.305 & USA \\
\hline The Bone $\theta$ Joint Journal & 3 & 500 & 167 & 2 & 1 & & & 4.306 & UK \\
\hline Acta Orthopaedica & 2 & 577 & 289 & & 1 & & 1 & 2.965 & UK \\
\hline Acta Orthopaedica et Traumatologica Turcica & 2 & 100 & 50 & & 2 & & & 1.121 & Turkey \\
\hline American Journal of Roentgenology & 2 & 84 & 42 & 1 & 1 & & & 3.190 & USA \\
\hline BMC Anesthesiology & 2 & 80 & 40 & 2 & & & & 1.720 & UK \\
\hline British Journal of Anaesthesia & 2 & 231 & 116 & 1 & 1 & & & 6.880 & UK \\
\hline Canadian Journal of Anaesthesia & 2 & 126 & 63 & & 2 & & & 3.280 & Canada \\
\hline Clinics in Orthopedic Surgery & 2 & 90 & 45 & 1 & 1 & & & 1.310 & $\begin{array}{l}\text { South } \\
\text { Korea }\end{array}$ \\
\hline European Radiology & 2 & 410 & 205 & 1 & 1 & & & 4.101 & Germany \\
\hline International Orthopaedics & 2 & 192 & 96 & 1 & 1 & & & 2.854 & Germany \\
\hline Journal of Anesthesia & 2 & 194 & 97 & 1 & 1 & & & 1.628 & Japan \\
\hline Journal of Orthopaedic $\theta$ Sports Physical Therapy & 2 & 194 & 97 & 1 & 1 & & & 3.839 & USA \\
\hline European Journal of Orthopaedic Surgery $\theta$ Traumatology & 2 & 129 & 65 & 1 & 1 & & & 1.560 & Germany \\
\hline Medicine & 2 & 192 & 96 & 1 & 1 & & & 1.552 & USA \\
\hline
\end{tabular}

IF, impact factor; LOE, level of evidence.

repeating authors in any position of authorship showed J. H. Oh, ${ }^{24-31}$ to be a contributing author in 8 unique studies; R. Z. Tashjian, in 6 studies $^{18-20,22,23,32}$; S. H. Kim, in 5 studies $^{24,26,29,31,33}$; and N. Maffulli, ${ }^{9-11,34}$ and J. C. Yoo ${ }^{35-38}$ in 4 studies published over a range of 12 years (2006-2018). Sixty-three other authors were listed as contributing authors in either 2 or 3 studies each.

\section{Journals}

Of the subcategories with strong and moderate recommendation strength, the Journal of Shoulder $\theta$ Elbow Surgery was the journal to be cited most frequently with 19 citations total. This was followed by Arthroscopy: Journal of Arthroscopic and Related Surgery with 18 citations and the American Journal of Sports Medicine with 13 citations. A comprehensive list of journals cited in the guideline along with citation frequency is shown in Table 3.

In the subcategories with strong recommendation strength, the Journal of Shoulder $\theta$ Elbow Surgery had the greatest number of cited articles, with the guideline referencing 11 published studies, of which 5 were classified as evidence level 1. It's noted, however, that the American Journal of Sports Medicine contained the greatest number of evidence level 1 studies (7) cited by these subcategories. The referenced studies published in the Journal of Bone and Joint Surgery also had the greatest number of total patients $(n=1724)$, while the referenced studies published in Acta Orthopaedica had the greatest average patient per study $(n=289)$. Journals originating in the United States were referenced the most frequently (41). Journals that were cited within subcategories with strong recommendation strength are further summarized in Table 4.

In the moderate-recommendation strength subcategory, Arthroscopy: Journal of Arthroscopic and Related Surgery (11) and evidence level 1 studies (6) cited by the CPG. The American Journal of Sports Medicine had the greatest number of total patients $(n=898)$ with five cited studies, and the highest average study density of 180 patients per study. Journals originating in the United States were referenced the most frequently (35). Journals that were cited within subcategories with moderate recommendation strength are further summarized in Table 5.

\section{Discussion}

We found that the 2019 AAOS CPG are based on a diverse number of journals and authors. We observed a prompt time from publication to implementation in the Guidelines, indicating that relatively recent clinical studies can influence clinical practice guidelines, while also including many well-established studies. Although several specific authors and journals were identified as being cited relatively more frequently, there was no 
Table 4. Journals Cited in Strong Recommendation Strength Guideline Subcategories

\begin{tabular}{|c|c|c|c|c|c|c|c|}
\hline Journal & $n$ Articles & $n$ Patients & $\begin{array}{c}\text { Mean Patients } \\
\text { per Study }\end{array}$ & LOE 1 & LOE 2 & 2019 IF & Country \\
\hline Journal of Shoulder $\theta$ Elbow Surgery & 11 & 1614 & 147 & 5 & 3 & 2.817 & USA \\
\hline American Journal of Sports Medicine & 10 & 1259 & 126 & 7 & 1 & 5.810 & USA \\
\hline Arthroscopy: Journal of Arthroscopic and Related Surgery & 7 & 462 & 66 & 2 & 5 & 4.325 & USA \\
\hline Journal of Bone and Joint Surgery & 6 & 1724 & 287 & 6 & & 4.578 & USA \\
\hline Radiology & 5 & 377 & 75 & 1 & 3 & 7.931 & USA \\
\hline Skeletal Radiology & 4 & 567 & 142 & 2 & & 1.618 & Germany \\
\hline Archives of Orthopaedic and Trauma Surgery & 3 & 371 & 124 & 1 & & 2.021 & Germany \\
\hline Knee Surgery, Sports Traumatology, Arthroscopy & 3 & 360 & 120 & 1 & 2 & 3.166 & Germany \\
\hline Acta Orthopaedica et Traumatologica Turcica & 2 & 100 & 50 & & 2 & 1.121 & Turkey \\
\hline American Journal of Roentgenology & 2 & 84 & 42 & 1 & 1 & 3.190 & USA \\
\hline European Radiology & 2 & 410 & 205 & 1 & 1 & 4.101 & Germany \\
\hline International Orthopaedics & 2 & 192 & 96 & 1 & 1 & 2.854 & Germany \\
\hline The Bone $\theta$ Joint Journal & 2 & 341 & 171 & 1 & 1 & 4.306 & UK \\
\hline
\end{tabular}

IF, impact factor; LOE, level of evidence.

widespread evidence for bias in this regard. It should be expected that leading journals in the field would, in fact by default, be cited more frequently and/or be more likely to include authors that are leaders in the field.

Generally, the implementation of scientific research into clinical practice can be a slow and cumbersome process. The present study demonstrates the lag time between publication research and the adoption of new best clinical practice. During the 10-year period between updates of the rotator cuff CPG, numerous valuable studies were published, many of which were within 2 years of the most recent guideline. The results of many of these studies may have been excluded from the guideline had it been updated sooner than 10 years from the originally published CPG. However, given the time and resources necessary to produce the CPG, more frequent updates may not be feasible. One notable technique used by the AAOS to further decrease the potential drawbacks associated with delaying the adoption of research was to publish an interim appropriate use criterion (AUC) for the application of previously established clinical practice guidelines. ${ }^{39}$ The
AAOS reviewed current literature and referenced expert opinion to assess the appropriateness of the 2010 guidelines on topics not supported by gold standard RCTs at the time. By doing so, they created an appropriateness rating to ensure that expected benefits of treatment substantially outweighed potential risks. This allowed patients to continue to receive high-quality care, potentially offsetting the disadvantage associated with time lag between scientific research and updated clinical practice guidelines. ${ }^{40}$

In analyzing the CPG, we identified many researchers, with only 5 individuals sharing authorship in greater than 3 studies each between 1994 and 2018. Of these studies, J. H. Oh and R. Z. Tashjian were listed as contributing authors in a total of 14 articles cited by the CPG. However, 63 unique authors contributed to either 2 or 3 studies each. Thus, although some repeated authors were noted within the 2019 AAOS CPG, they made up a small number of the total studies. The present analysis of 2019 AAOS CPG discovered a diverse group of authorship that was not dominated by only a few voices in the field.

Table 5. Journals Cited in Moderate Recommendation Strength Guideline Subcategories

\begin{tabular}{|c|c|c|c|c|c|c|c|}
\hline Journal & $n$ Articles & $n$ Patients & $\begin{array}{c}\text { Mean Patients } \\
\text { per Study }\end{array}$ & LOE 1 & LOE 2 & 2019 IF & Country \\
\hline Arthroscopy: Journal of Arthroscopic and Related Surgery & 11 & 706 & 64 & 6 & 4 & 4.325 & USA \\
\hline Journal of Shoulder $\theta$ Elbow Surgery & 9 & 813 & 90 & 3 & 4 & 2.817 & USA \\
\hline Journal of Bone and Joint Surgery & 7 & 754 & 108 & 5 & 1 & 4.578 & USA \\
\hline Knee Surgery, Sports Traumatology, Arthroscopy & 6 & 397 & 66 & 5 & 1 & 3.166 & Germany \\
\hline American Journal of Sports Medicine & 5 & 898 & 180 & 2 & 1 & 5.810 & USA \\
\hline Anesthesia $\theta$ Analgesia & 3 & 180 & 60 & 1 & 2 & 4.305 & USA \\
\hline BMC Anesthesiology & 2 & 80 & 40 & 2 & & 1.720 & UK \\
\hline British Journal of Anaesthesia & 2 & 231 & 116 & 1 & 1 & 6.880 & UK \\
\hline Canadian Journal of Anaesthesia & 2 & 126 & 63 & & 2 & 3.280 & Canada \\
\hline Clinics in Orthopedic Surgery & 2 & 90 & 45 & 1 & 1 & 1.310 & South Korea \\
\hline Journal of Anesthesia & 2 & 194 & 97 & 1 & 1 & 1.628 & Japan \\
\hline
\end{tabular}

IF, impact factor; LOE, level of evidence. 


\section{Limitations}

There are limitations worth noting in this study. We specifically analyzed articles that contributed to strong and moderate recommendations of the CPG. Thus, articles not referenced by the CPG were not included. However, utilization of a more expansive inclusion criteria could reveal high-quality studies supporting CPG recommendations, possibly affecting the present analysis of lag time. The present study also used a single ranking system published by Marx et al. ${ }^{41}$ and recommended by the Journal of Bone and Joint Surgery to assign level of evidence to studies without a self-published grade. Given the existence of numerous classification systems, we acknowledge that the use of a single ranking system, selected by the present authors, may be viewed as a limitation. However, the assigned level of evidence based on this ranking system did not conflict with those self-reported by individual studies in the CPG. Hence, this ranking system was found to be the most appropriate within the context of the papers reviewed.

\section{Conclusion}

The 2019 AAOS CPG reference a diverse number of journals and authors, appearing to be impartial. Furthermore, prompt time from publication to implementation in the Guidelines indicates that it is possible to influence clinical guidelines with recent work.

\section{References}

1. Westfall JM, Mold J, Fagnan L. Practice-based research-"Blue Highways" on the NIH roadmap. JAMA 2007;297:403-406. doi:10.1001/jama.297.4.403.

2. Balas EA, Boren SA. Managing clinical knowledge for health care improvement. Yearb Med Inform 2000;1:65-70.

3. Morris ZS, Wooding S, Grant J. The answer is 17 years, what is the question: Understanding time lags in translational research. $J R$ Soc Med 2011;104:510-520. doi:10. 1258/jrsm.2011.110180.

4. Ward V, House A, Hamer S. Developing a framework for transferring knowledge into action: A thematic analysis of the literature. J Health Serv Res Policy 2009;14:156-164. doi:10.1258/jhsrp.2009.008120.

5. Pedowitz RA, Yamaguchi K, Ahmad CS, et al. Optimizing the management of rotator cuff problems. J Am Acad Orthop Surg 2011;19:368-379. doi:10.5435/ 00124635-201106000-00007.

6. Weber S, Chahal J. Management of rotator cuff injuries. J Am Acad Orthop Surg 2020;28:193-201. doi:10.5435/ JAAOS-D-19-00463.

7. Wright JG, Swiontkowski MF, Heckman JD. Introducing levels of evidence to the journal. J Bone Jt Surg 2003;85: $1-3$.

8. Brown G, Weber S, Chahal J, et al. Management of Rotator Cuff Injuries Clinical Practice Guideline 2019. https://www.aaos. org/quality/quality-programs/upper-extremity-programs/ rotator-cuff-injuries/. Accessed 2020.
9. Franceschi F, Papalia R, Franceschetti E, et al. Double-row repair lowers the retear risk after accelerated rehabilitation. Am J Sports Med 2016;44:948-956. doi:10.1177/ 0363546515623031.

10. Franceschi F, Ruzzini L, Longo UG, et al. Equivalent clinical results of arthroscopic single-row and double-row suture anchor repair for rotator cuff tears: A randomized controlled trial. Am J Sports Med 2007;35:1254-1260. doi: 10.1177/0363546507302218.

11. Franceschi F, Papalia R, Del Buono A, et al. Articularsided rotator cuff tears: Which is the best repair? A threeyear prospective randomised controlled trial. Int Orthop 2013;37:1487-1493. doi:10.1007/s00264-013-1882-9.

12. Lee JJ, Hwang J-T, Kim D-Y, et al. Effects of arthroscopyguided suprascapular nerve block combined with ultrasound-guided interscalene brachial plexus block for arthroscopic rotator cuff repair: A randomized controlled trial. Knee Surg Sports Traumatol Arthrosc 2017;25: 2121-2128. doi:10.1007/s00167-016-4198-7.

13. Lee JJ, Yoo Y-S, Hwang J-T, et al. Efficacy of direct arthroscopy-guided suprascapular nerve block after arthroscopic rotator cuff repair: a prospective randomized study. Knee Surg Sports Traumatol Arthrosc 2015;23: 562-566. doi:10.1007/s00167-013-2451-x.

14. Lee JJ, Kim D-Y, Hwang J-T, et al. Effect of ultrasonographically guided axillary nerve block combined with suprascapular nerve block in arthroscopic rotator cuff repair: A randomized controlled trial. Arthroscopy 2014;30: 906-914. doi:10.1016/j.arthro.2014.03.014.

15. Moosmayer S, Gärtner AV, Tariq R. The natural course of nonoperatively treated rotator cuff tears: An 8.8-year follow-up of tear anatomy and clinical outcome in 49 patients. J Shoulder Elbow Surg 2017;26:627-634. doi:10. 1016/j.jse.2016.10.002.

16. Moosmayer S, Lund G, Seljom US, et al. Tendon repair compared with physiotherapy in the treatment of rotator cuff tears: A randomized controlled study in 103 cases with a five-year follow-up. J Bone Joint Surg Am 2014;96: 1504-1514. doi:10.2106/JBJS.M.01393.

17. Moosmayer S, Heir S, Smith H-J. Sonography of the rotator cuff in painful shoulders performed without knowledge of clinical information: Results from 58 sonographic examinations with surgical correlation. $J$ Clin Ultrasound 2007;35:20-26. doi:10.1002/jcu. 20286.

18. Wylie JD, Baran S, Granger EK, Tashjian RZ. A comprehensive evaluation of factors affecting healing, range of motion, strength, and patient-reported outcomes after arthroscopic rotator cuff repair. Orthop J Sport Med 2018;6:2325967117750104. doi: 10.1177/232596711775 0104.

19. Chalmers PN, Granger E, Nelson R, Yoo M, Tashjian RZ. Factors affecting cost, outcomes, and tendon healing after arthroscopic rotator cuff repair. Arthroscopy 2018;34: 1393-1400. doi:10.1016/j.arthro.2017.11.015.

20. Potter MQ, Wylie JD, Granger EK, Greis PE, Burks RT, Tashjian RZ. One-year patient-reported outcomes after arthroscopic rotator cuff repair do not correlate with mild to moderate psychological distress. Clin Orthop Relat Res 2015;473:3501-3510. doi:10.1007/s11999-0154513-5. 
21. Namdari S, Baldwin K, Glaser D, Green A. Does obesity affect early outcome of rotator cuff repair? J shoulder Elb Surg 2010;19:1250-1255. doi:10.1016/j.jse.2010.03.003.

22. Tashjian RZ, Henn RF, Kang L, Green A. Effect of medical comorbidity on self-assessed pain, function, and general health status after rotator cuff repair. J Bone Joint Surg Am 2006;88:536-540. doi:10.2106/JBJS.E.00418.

23. Henn RF, Kang L, Tashjian RZ, Green A. Patients' preoperative expectations predict the outcome of rotator cuff repair. J Bone Joint Surg Am 2007;89:1913-1919. doi:10. $2106 / J B J S . F .00358$.

24. Park JS, Park HJ, Kim SH, Oh JH. Prognostic factors affecting rotator cuff healing after arthroscopic repair in small to medium-sized tears. Am J Sports Med 2015;43: 2386-2392. doi:10.1177/0363546515594449.

25. Oh JH, Kim JY, Choi JH, Park S-M. Is arthroscopic distal clavicle resection necessary for patients with radiological acromioclavicular joint arthritis and rotator cuff tears? A prospective randomized comparative study. Am J Sports Med 2014;42:2567-2573. doi:10.1177/ 0363546514547254.

26. Chung SW, Park JS, Kim SH, Shin SH, Oh JH. Quality of life after arthroscopic rotator cuff repair: Evaluation using SF-36 and an analysis of affecting clinical factors. Am J Sports Med 2012;40:631-639. doi:10.1177/ 0363546511430309.

27. Lee H, Ahn JM, Kang Y, et al. Evaluation of the subscapularis tendon tears on $3 \mathrm{~T}$ magnetic resonance arthrography: Comparison of diagnostic performance of Tl-weighted spectral presaturation with inversionrecovery and T2-weighted turbo spin-echo sequences. Korean J Radiol 2018;19:320-327. doi:10.3348/kjr.2018. 19.2.320.

28. Shin S-J, Oh JH, Chung SW, Song MH. The efficacy of acromioplasty in the arthroscopic repair of small- to medium-sized rotator cuff tears without acromial spur: Prospective comparative study. Arthroscopy 2012;28: 628-635. doi:10.1016/j.arthro.2011.10.016.

29. Han SS, Lee YH, Oh JH, Aminzai S, Kim SH. Randomized, controlled trial of multimodal shoulder injection or intravenous patient-controlled analgesia after arthroscopic rotator cuff repair. Knee Surg Sports Traumatol Arthrosc 2013;21:2877-2883. doi:10.1007/ s00167-012-2202-4.

30. Yun MJ, Oh JH, Yoon JP, Park SH, Hwang JW, Kil HY. Subacromial patient-controlled analgesia with ropivacaine provides effective pain control after arthroscopic rotator cuff repair. Knee Surg Sports Traumatol Arthrosc 2012;20:1971-1977. doi:10.1007/s00167-011-1841-1.

31. Oh JH, Rhee K-Y, Kim SH, Lee P-B, Lee J-W, Lee SJ. Comparison of analgesic efficacy between single interscalene block combined with a continuous intrabursal infusion of ropivacaine and continuous interscalene block after arthroscopic rotator cuff repair. Clin Orthop Surg 2009;1:48-53. doi:10.4055/cios.2009.1.1.48.

32. Thackeray EM, Swenson JD, Gertsch MC, et al. Diaphragm function after interscalene brachial plexus block: A double-blind, randomized comparison of $0.25 \%$ and 0 . 125\% bupivacaine. J shoulder Elbow Surg 2013;22: 381-386. doi:10.1016/j.jse.2012.06.011.

33. Kim DH, Jang YH, Choi YE, Lee H-R, Kim SH. Evaluation of repair tension in arthroscopic rotator cuff repair: Does it really matter to the integrity of the rotator cuff? $A m \mathrm{~J}$ Sports Med 2016;44:2807-2812. doi:10.1177/ 0363546516651831.

34. Osti L, Buono A Del, Maffulli N. Pulsed electromagnetic fields after rotator cuff repair: A randomized, controlled study. Orthopedics 2015;38:223-228. doi:10.3928/ 01477447-20150305-61.

35. Ryu HY, Song SY, Yoo JC, Yun JY, Yoon YC. Accuracy of sagittal oblique view in preoperative indirect magnetic resonance arthrography for diagnosis of tears involving the upper third of the subscapularis tendon. J Shoulder Elbow Surg 2016;25:1944-1953. doi:10.1016/j.jse.2016. 02.038.

36. Oh DK, Yoon YC, Kwon JW, et al. Comparison of indirect isotropic $\mathrm{MR}$ arthrography and conventional MR arthrography of labral lesions and rotator cuff tears: A prospective study. AJR Am J Roentgenol 2009; 192:473-479. doi:10.2214/AJR.08.1223.

37. Koh KH, Kang KC, Lim TK, Shon MS, Yoo JC. Prospective randomized clinical trial of single- versus double-row suture anchor repair in 2- to 4 -cm rotator cuff tears: clinical and magnetic resonance imaging results. Arthroscopy 2011;27:453-462. doi:10.1016/j. arthro.2010.11.059.

38. Koh KH, Lim TK, Shon MS, Park YE, Lee SW, Yoo JC. Effect of immobilization without passive exercise after rotator cuff repair: Randomized clinical trial comparing four and eight weeks of immobilization. J Bone Joint Surg Am 2014;96:44. doi:10.2106/JBJS.L.01741.

39. Murray J, Gross L. Optimizing the management of fullthickness rotator cuff tears. J Am Acad Orthop Surg 2013;21:767-771. doi:10.5435/JAAOS-21-12-767.

40. Cowan JB, Bedi A, Carpenter JE, Robbins CB, Gagnier JJ, Miller BS. Evaluation of American Academy of Orthopaedic Surgeons appropriate use criteria for the management of full-thickness rotator cuff tears. J shoulder Elb Surg 2016;25:1100-1106. doi:10.1016/j.jse.2015.12.009.

41. Marx RG, Wilson SM, Swiontkowski MF. Updating the assignment of levels of evidence. J Bone Jt Surg 2015;97: 1-2. doi:10.2106/JBJS.N.01112. 